\title{
Influences of Culture in the Built Environment; Assessing Living Convenience in Kabul City
}

\author{
Osama Hidayat ${ }^{1, *(\mathbb{D})}$ and Yoshitaka Kajita ${ }^{2}$ \\ 1 Graduate School of Science and Engineering, Tokai University, Kanagawa 259-1207, Japan \\ 2 Department of Civil Engineering, Faculty of Engineering, Tokai University, Kanagawa 259-1207, Japan; \\ yokaji@tokai-u.jp \\ * Correspondence: osama.hidayat@gmail.com
}

Received: 18 August 2020; Accepted: 16 September 2020; Published: 18 September 2020

\begin{abstract}
During Afghanistan's rapid urban growth, development diversified from state-run initiatives to ones led by local municipalities or nongovernmental entities such as private enterprises. Owing to these various efforts, cities face environmental challenges, squatter settlements, and unbalanced development. Responding to these interconnected challenges, cities need to increase their resilience to deal with the combined effects of urbanization, changing geopolitical contexts, and culture. In this study, we focused on dimensions of culturally responsive solutions for the built environment in Kabul, Afghanistan. Culture, as a key element in the concept of sustainable development, refers herein to the relationship between Afghan customs and belief systems as it influences and shapes the architecture of the urban environment. Initially, the study provides a conceptual understanding of sustainable urban development and the importance of culture. We have attempted to approach urban segregation in Kabul based on socioeconomic factors and address the essential role of culture in this unique context. Such segregation can be hazardous to both the current and future sustainability of urban development. To conclude, we provide in-depth insights into the contribution of culture and propose culture as a possible dimension of sustainability and an integral part of environmental, economic, and social dimensions of development.
\end{abstract}

Keywords: informal urbanism; culture; sustainable urban development; urban management; Kabul

\section{Introduction}

The urban planning of Kabul City was strongly influenced by the Soviet master planning attempts, which started in the 1960s and continued to prevail until the end of the twentieth century. Despite the fact that the Soviet master plans were not fully implemented, their strong impact is still evident in the planning system of Afghanistan.

Two important events that had an immense negative impact on the development Kabul were the soviet war of December 1979-February 1989 and the Afghan civil war of 1992-1996, in which the majority of the city's infrastructure was destroyed, and the social fabric of the city was torn apart. This was followed by the five-year rule of the Taliban, which prevented any reconstruction effort.

In 2001, by the invasion of coalition forces, an interim government in Afghanistan was established and a new era of urban development began. The relative stability of post-conflict Kabul paved the way for vast reconstruction efforts. Meanwhile, the massive return of refugees and internally displaced people to major cities, especially Kabul, resulted in the emergence of many new challenges. Over seventy percent of the Kabul City area was occupied by informal settlements with no or limited access to basic services and infrastructure. The new situation created conflict in relation to planning ideas for the future of Kabul City. The ideas varied from reviving the Soviet master plans to new planning solutions for the existing city, as well as the proposal for a new city to the north of the existing 
Kabul City. These approaches have resulted in the production of plans on paper, and inappropriate policies and standards as well as problems of enforcement have resulted in the volume of illegal development generally exceeding that of legal development [1]. Moreover, where regulations have been enforced, they have had negative effects on land and housing markets, which result in higher costs. It has been argued that issues of culture and decision making need more attention in the form of analysis, policy, and practice. In short, the top priority is to devise better governance arrangements.

Planning implies the identification of problems, the exploration and analysis of alternative courses of action, and the making of decisions. Traditionally, spatial planning has been dominated by urban planners using tools such as master plans-blueprint plans specifying the desired pattern of urban development 15 to 20 years in the future [2].

Moving forward on the meaning of culture, our study elaborates the importance and validity of culture in this era of urbanization and its role in the design of the built environment within the particular context of Afghanistan. In the quest to achieve sustainable urban development (SUD) in Kabul City, there are several challenges, such as inadequate financial resources to plan and realize sustainable development (often not possible because of conflicting priorities), insufficient effort applied at a municipal level, and corruption [3].

However, current trends and projections suggest that urbanization will continue in both developed and developing countries. Overall, it is expected that seven out of 10 people will be living in cities by 2050 [4]. These social trends and natural phenomena have demonstrated that the urban environment and associated planning policies should be regarded as crucial research topics more than ever before. On the basis of the current status and development processes, in this study, we especially aimed for SUD and its dynamics according to international experience in advanced countries. Numerous scholars, both nationally and internationally, believe that effective urban planning policies greatly contribute to improving the urban built environment. However, comprehensively enhancing the built environment or solving all relevant urban issues from the perspective of sustainable development alone is certainly impossible. The main objective of our study has been to contribute to filling the gap in the research on the role of culture in achieving urban sustainability by examining how socioeconomic challenges relate to that development goal. To that end, we sought to define urban sustainability by considering the complexity of urban systems, along with cultural factors such as intellectual disciplines and systems of thought. Planning according to local conditions and civic engagement in decision making can play significant roles in enabling cities to deal with a complex system and changing conditions [5].

This research sought to identify the current trends of development and to identify pathways forward for future planning and interventions through policy. The underlying assumption subsequently confirmed during the research was that "return" to the place of origin was not a viable option for most of the unplanned settlements. Hence, this research conceptualized the development of Kabul not as a temporary growth due to displacement but as a process of upgrading, a prevalent phenomenon faced in major cities in less developed countries around the world. [6]

The rest of the paper is structured as follows: Section 2 sets the context for later sections by describing the background of the research and by conducting a literature review; Section 3 explains the research methods and materials; and Section 4 explores the implications of cultural dimensions for achieving urban sustainability. The final section provides a discussion and synthesis as well as some suggested ideas for future improvement.

\section{Literature Review and Background}

In the literature review, we examined works on culture, sustainable development, and the link between culture and sustainability in the built environment. We aimed to clearly identify the knowledge gap regarding the role of culture in a SUD. Our critical review of the literature helped us understand the structure of the subject, distinguish what is known from what is unknown, establish the significance of the problem under study, seek new lines of enquiry, and ascertain the key variables essential to the issue. 
Several researchers have argued that one of the most significant and cost-effective ways to foster the prevalent use of sustainable practices is setting a comprehensible set of codes, standards and policy. With regard to "urban culture and heritage", a Habitat III-issued paper by the United Nations Educational, Scientific and Cultural Organization (UNESCO) notes that the contemporary urban crisis requires a new model of urban development. The model must increase social cohesion, counter segregation (social and spatial) and the uneven distribution of wealth and aim for more equitable distribution and access to urban resources and more integration and connection among residents. Furthermore, it needs to follow the laws of Islam and incorporate the conservative Islamic culture and Afghan culture (Afghan wali) of Afghan residents (M.S. Sharifzai).

In Kabul, a key player in customary urban development system is the "Wakil-e-gozar", a representative elected by heads of households in a neighborhood. As well as his legal responsibility to register births, marriages, deaths, a wakil can also wield considerable influence through his role in endorsing the registration of property, in resolving disputes and in advocating for his community in the corridors of power. (A. W. Najimi and Jolyon Leslie) [7]. Their capacity for unprofessional decision making and the lack of development frameworks from the government sector must be remedied through the application of sustainable methods; conflicts between authorities due to gaps or overlaps in the functions of organizations is a common feature of the current institutions of Afghanistan, which in many cases have led to infeasible decisions and a waste of resources.

Cultural sustainability is attainable by careful examining socio-economic characteristics and urban patterns in rapidly developing cities and benefitting from their design essence and principles. It is possible to formulate a set of design and planning strategies that generate and nourish the necessary cultural matrix and community bonds, but also apply to the lifestyle of the 21st century (B. A. Kazimee) [8].

In this section, we present a review of the literature concerning the role of culture in SUD.

\section{Role of Culture in SUD}

The built environment is a complex system that shapes enormous resource flows (i.e., material, energy, labor, and economic investment) and impacts the natural environment for decades. If one considers the typical design, construction, and maintenance practices used today, the relationship between the built environment and the natural environment is not sustainable. We propose that new, multidisciplinary approaches be applied to the design, construction, maintenance, and reuse of the built environment to make it more sustainable and to dramatically reduce its impacts. The sooner we change to more sustainable building practices, the faster we will make progress toward truly SUD [9].

The standard dictionary definition of culture includes customary beliefs, social forms, and material traits of a racial, religious, or social group. Within discourses led by actors of the (urban) cultural sector and in parts of the urban cultural policy discourse (by researchers and practitioners), questions of SUD have been increasingly discussed. International networks-such as the "Agenda 21 for Culture" carried by United Cities and Local Governments, the European Cooperation in Science and Technology Action "Investigating Cultural Sustainability" (2011-2015), or the "Culture 21" network-have been promoting the idea to integrate concepts and research concerning culture into SUD policy.

To clarify cultural conditions for research within the context of Sustainable development, we investigated how culture is being discussed in two major and often interconnected areas of SUD discourse: academic writings (of the scientific community of sustainability science [10]) and the public mainstream discourse (of urban politics led by city governments, administrative institutions and their representatives, and international organizations). The extent of culture's role in sustainable urban development concepts and policy measures depends also on idiosyncratic (local) discourses and on actors. At first sight, in sustainability science as well as in mainstream political discourse, culture in the urban context still plays a subordinate role. Not many relevant publications exist in the academic context, nor is culture specified as a crucial field of action on the policy level. Most approaches focus 
on a set of topics and challenges that are based on typical "green" themes. However, cultural concepts or questions are addressed in some contexts.

A cultural approach to SUD is thus not limited to traditionally conceived "cultural policy" (as defended by, e.g., the International Journal of Cultural Policy), nor to specific areas such as heritage protection, public art, building in local character, and the organization of temporary events (e.g., art festivals) but instead revitalizes a broader approach, echoing the definition of culture in urban planning [8]. Thus, culture creates solid bridges with the other three dimensions of development and is compatible with each of them.

\section{Research Design and Methodology}

It is possible to learn lessons by examining and analyzing the existing patterns of the urban form, not only to understand their physical artefacts and functional relations, but also to explore their specific cultural and social meaning, which is intimately bound to the emotional and spiritual philosophies of the people.

For this study, we adopted the case study methodology with a triangulation data collection method and mixed-method data analysis. The primary data used herein were collected from surveys (using on-site and emailed questionnaires concerning public satisfaction and visual preference) that we had distributed across the study area. In Kabul City, we targeted four districts or precincts; 5 neighborhoods were surveyed in each district, and 10 households were randomly chosen to be interviewed in each neighborhood. A total of 200 questionnaire surveys were retrieved and analyzed. We used Likert scale-type questions for determining services and facilities' adequacy; accordingly, respondents were required to rank questions from 1 to 5 , where 1 represented very inadequate; 2 , inadequate; 3 , neutral; 4 , adequate; and 5, very adequate. We also obtained secondary data from previous research and from design documents created by government and nongovernment organizations in Afghanistan. Our study also included site observations corresponding to the questionnaire surveys.

The findings of the questionnaire were then used to develop a framework for the sustainable development of communities and urban patterns.

\section{Study Area}

The study area (Figure 1) was meticulously chosen on the basis of theoretical and practical evidence of urban issues in Kabul City as a case of a developing country in the process of mitigating SUD challenges. In our study, we sought to understand the concept and characteristics of an urban system and the role of culture. We hypothesized that there is a significant relationship between the residents' socioeconomic living conditions and urban conditions. Therefore, we investigated the socioeconomic and environmental characteristics of the study area to understand the issues for devising adequate improvement strategies [11].

The socioeconomic, physical, and environmental characteristics along with government reports and previous research on Kabul City reflect unsustainable development trends. The city is situated at lat. $34.53 \mathrm{~N}$ and long. $69.17 \mathrm{E}$, and at $1798 \mathrm{~m}$ above sea level with a geographical area of $275 \mathrm{~km}^{2}$. Kabul, the capital of Afghanistan and the main city of the country with a population of 3.1 million, is now home to $41 \%$ of the total urban population of the country, of which $82 \%$ is informal. The 55 informal settlements in Kabul City accommodate a population of over 30,000 each [12]. 


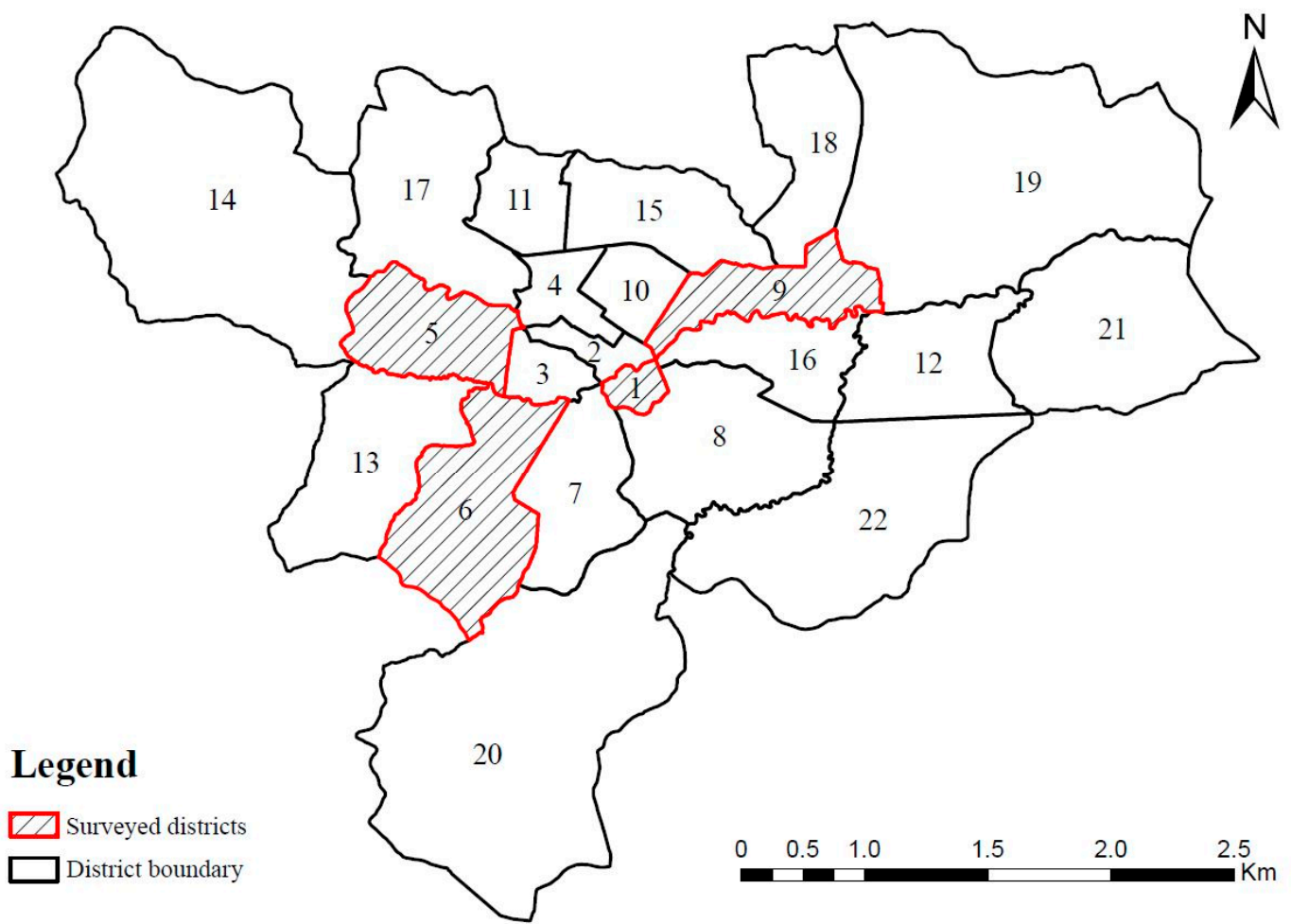

Figure 1. Map of Kabul City showing specific districts composing the study area (District 1-22).

\section{Case Study}

As a result of the rapid growth of the population in Kabul and the development of the city over the last 18 years, urban sprawl, urban inequality, and urban culture are considered to be major challenges for sustainable development.

District 1: Located centrally, it represents the old city of Kabul, which established its basic structure during the 1940s and 1950s with its main street, Jada-i-Maiwand. The district has 23 neighborhoods (gozars), and the number of households, population, and areas vary considerably by neighborhood. The urban area accounts for $65.3 \%$ of the district land, of which $46.6 \%$ is of high density. The eastern half of the district is mostly residential with high cultural value (Figure 2).

According to the 1978 Kabul City Master Plan, both sides of the Jada-i-Maiwand Street were planned for commercial purposes. The area between the upper and lower main roads and the area along the foot of the hills are residential mixed-use areas. Except for the hillside area, the residential areas are the oldest in Kabul City [13]. Because the area is considered to be a historic part of the city, construction is less active in these residential areas, and people still rely on traditional construction materials and methods, even for the rebuilding and repair of old buildings.

The majority of the district has been developed through informal settlements over the past 20 years, owing to rapid urban growth, including rural-urban migration. More than $70 \%$ of the residents who live around the hill slope areas have no legal documents showing ownership of their properties. They face poor living conditions, particularly problems with water supply, solid waste disposal, and sanitation [14] (ISBN: 978-951-39-6177-0). 


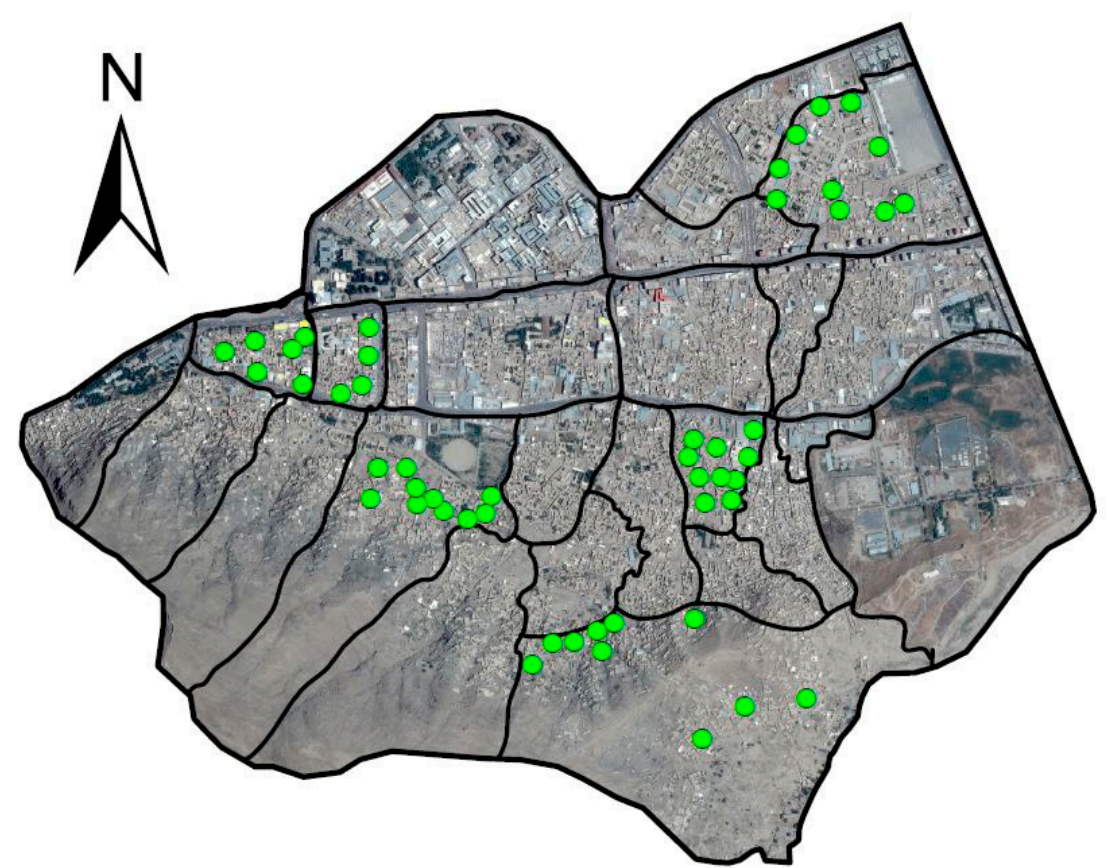

\section{Legend}

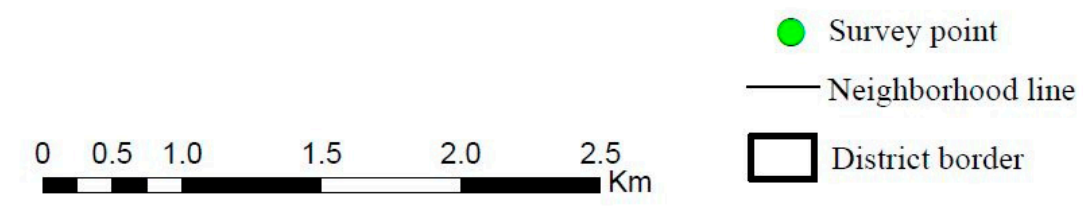

Figure 2. Map of District 1 with neighborhood boundaries and investigated sites.

District 5: Located in the western part of Kabul City, it has 42 existing neighborhoods, and the land area is 2924 ha, of which $41.21 \%$ is residential. The major educational institutions, including Kabul University, and the Afghan Ministry of Higher Education are in this district. About $63 \%$ of the residential areas are developed in irregular shapes, and some camps for internally displaced people are located in different parts of the district. Most of the public facilities are in planned areas of the district, and the remaining areas generally have only very limited facilities. This has created a social gap between planned and unplanned settlements. Educational facilities cannot respond to the needs of the growing population. There is one government hospital and private clinics in the planned areas that are not responsive to the demands of the people [15]. Moreover, there are considerable problems in terms of solid waste management in the district (Figure 3). 


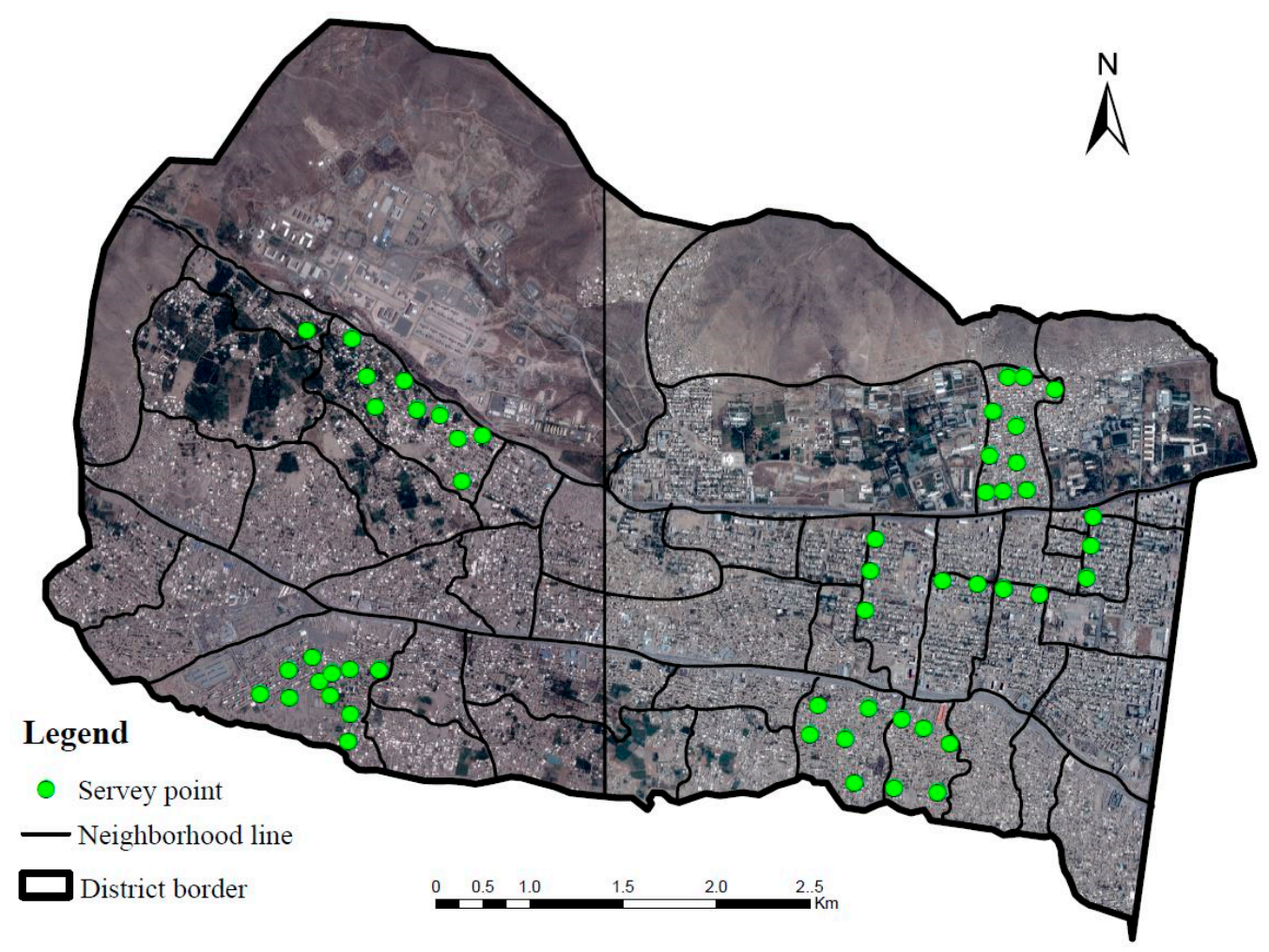

Figure 3. Map of District 5 with neighborhood boundaries and investigated sites.

District 6: This district is in the southwestern part of Kabul City; it is composed of 53 neighborhoods, and about $89 \%$ of the properties have been developed in irregular shapes. The district land area is $49.1 \mathrm{~km}^{2}$, of which $50.8 \%$ is mountainous and $32.5 \%$ is residential. Businesses and institutes are expanding along the main street, Darulaman Road. Because of the low socioeconomic profile of this district, street vendors are common and have caused serious traffic problems in some parts of the district. On the basis of the survey results, there is an unmet need for primary schools in unplanned areas within the district. As in the other districts, most facilities are concentrated in planned areas of the district, whereas unplanned areas lack facilities (Figure 4). 


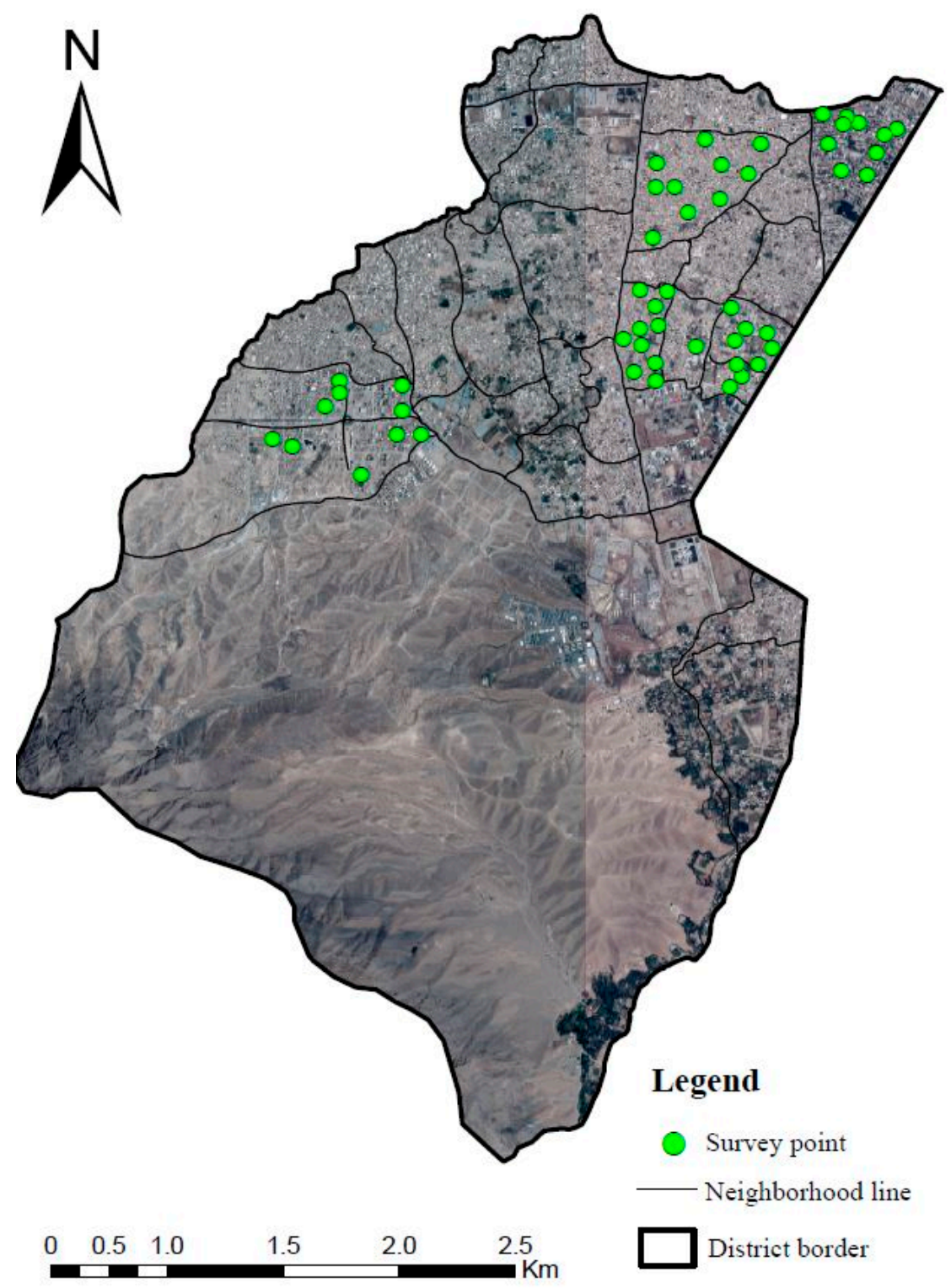

Figure 4. Map of District 6 with neighborhood boundaries and investigated sites.

District 16: This district is in the eastern part of Kabul City; it has 27 standardized neighborhoods (1000 to 1250 households in each neighborhood), which are also called cadastral territorial units. The standard neighborhoods are in numerical order, and traditional neighborhoods delineated by Kabul Municipality were named after different attributes such as people and cultural and historical people/events. The district has a land area of $25.2 \mathrm{~km}^{2}$, of which $54 \%$ is urbanized. The Makroryan housing complex contains the first luxury apartments built by the government in the capital, occupying 40.9 ha at the west end of the district. Agricultural land occupies 27\% of the land area, whereas vacant or barren land accounts for $13 \%$ of the district. As the access from the city center has improved by the new arterial road, the remaining agricultural land has been subjected to informal urbanization in the district (Figure 5) [16]. 


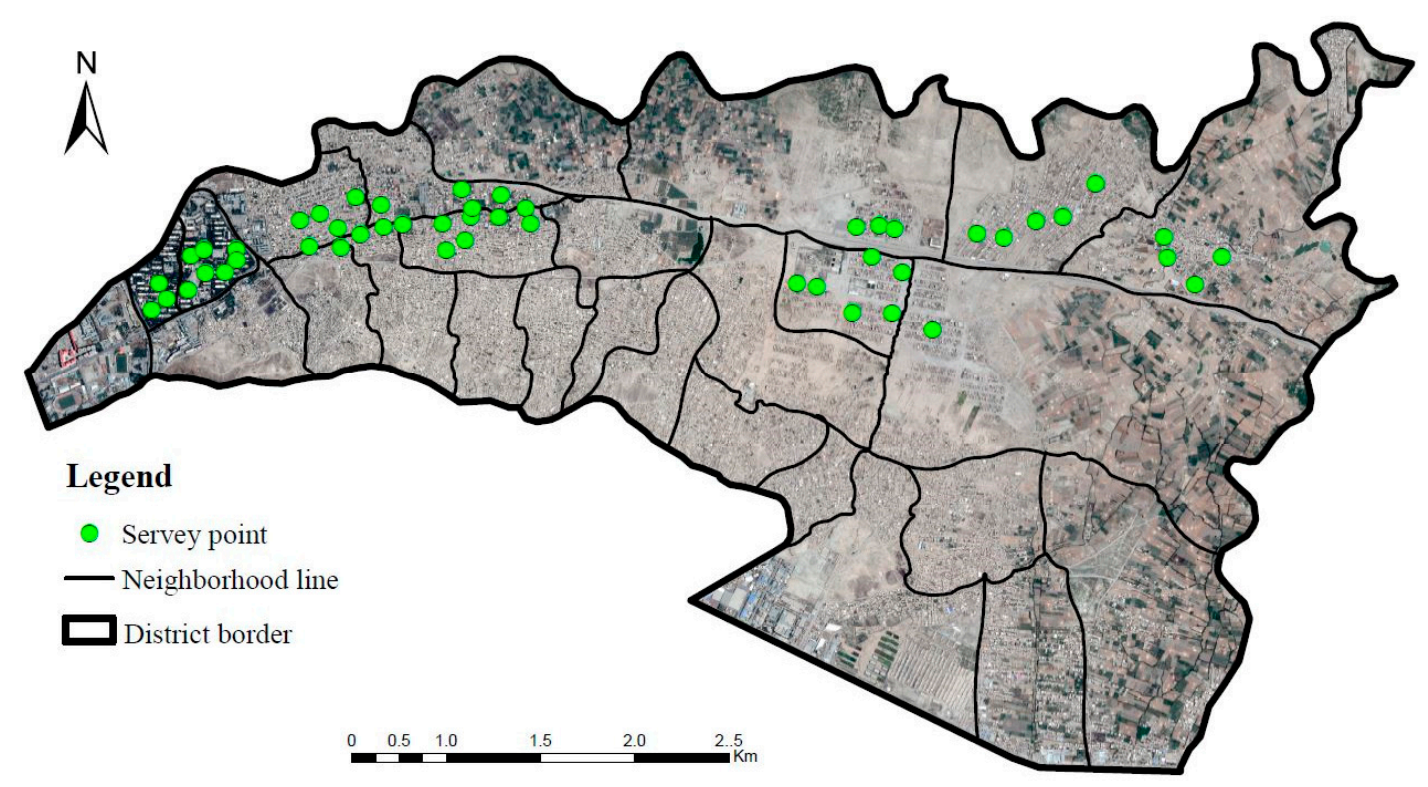

Figure 5. Map of District 16 with neighborhood boundaries and investigated sites.

\section{Empirical Research Analysis}

\subsection{Scope}

For this study, we selected four precincts/districts in Kabul City as the empirical study area because metropolitan areas are typically used as study subjects when measuring socio-economic indicators. The goal was to define urban sustainability by considering the complexity of urban systems. Moreover, other studies related to sustainable urban forms, such as that by Kazimee [17], have indicated that a powerful instrument in implementing sustainable development programs in cities is a determined populace, as they are the real stakeholders and users of the built environment. The people can play a key role in understanding and successfully realizing the true visions of sustainable urban goals in their communities.

\subsection{Findings}

The socioeconomic and environmental characteristics of the districts are not the same in several different ways (Table 1). In general, high school is the highest level of education for $35.66 \%$ of the people; private employment is the largest occupational group, at $39.03 \%$; the highest average monthly income is 20,000-50,000 AFN, at 31.28\%; the highest household size, between seven and nine individuals, is characteristic of $32.33 \%$; the average plot size for a house is $150-300 \mathrm{~m}^{2}$, at $43.94 \%$; and property values in the range of 20,000-50,000 USD form the largest group, at $42.55 \%$. The most common type of building $(41.03 \%)$ is flat-roofed with one to three floors, and these buildings are made of construction materials that comprise baked bricks. The highest number of households own their properties, at $54.63 \%$, whereas the majority (54.5\%) of settlements in the studied districts are informal, causing socioeconomic inadequacy that interrelates with an environmental threat to sustainable development. This is significant in the study areas, and it requires urgent sustainable strategies to improve the situation [18]. 
Table 1. Socioeconomic and environmental characteristics of study areas in Kabul City (based on author's 2018 fieldwork).

\begin{tabular}{|c|c|c|c|c|c|c|c|}
\hline \multirow{2}{*}{ No. } & \multirow{2}{*}{ Characteristic } & \multirow{2}{*}{ Category } & District 1 & District 5 & District 6 & District 16 & Total. \\
\hline & & & $\%$ & $\%$ & $\%$ & $\%$ & $\%$ \\
\hline \multirow{5}{*}{1} & \multirow{4}{*}{$\begin{array}{l}\text { Level of } \\
\text { Education }\end{array}$} & Primary & 12.24 & 17.42 & 12.9 & 11.11 & 13.4175 \\
\hline & & Secondary & 29.25 & 27.74 & 15.48 & 35.42 & 26.9725 \\
\hline & & High school & 33.33 & 28.39 & 40.65 & 40.28 & 35.6625 \\
\hline & & University & 25.18 & 26.45 & 30.97 & 13.19 & 23.9475 \\
\hline & Total & & 100 & 100 & 100 & 100 & 100 \\
\hline \multirow{6}{*}{2} & \multirow{5}{*}{ Occupation } & Public servant & 14.29 & 14.71 & 6.25 & 18.35 & 13.4 \\
\hline & & $\begin{array}{l}\text { Private } \\
\text { employed }\end{array}$ & 50 & 50 & 16.67 & 39.45 & 39.03 \\
\hline & & Business & 7.14 & 7.35 & 31.25 & 12.84 & 14.645 \\
\hline & & Street vendor & 10.71 & 10.29 & 22.91 & 9.17 & 13.27 \\
\hline & & Jobless & 17.86 & 17.65 & 22.92 & 20.19 & 19.655 \\
\hline & Total & & 100 & 100 & 100 & 100 & 100 \\
\hline \multirow{6}{*}{3} & \multirow{5}{*}{$\begin{array}{c}\text { Average } \\
\text { Monthly Income } \\
\text { (Afn) }\end{array}$} & $<10,000$ & 24.49 & 24.49 & 25 & 26.15 & 26.15 \\
\hline & & $10,000-20,000$ & 46.94 & 26.53 & 16.67 & 29.49 & 28.66 \\
\hline & & $20,000-50,000$ & 22.45 & 22.45 & 33.33 & 28.57 & 26.27 \\
\hline & & $50,000-100,000$ & 4.08 & 18.37 & 18.75 & 12.25 & 13.37 \\
\hline & & $>100,000$ & 2.04 & 8.16 & 6.25 & 4.08 & 5.14 \\
\hline & Total & & 100 & 100 & 100 & 100 & 100 \\
\hline \multirow{5}{*}{4} & \multirow{4}{*}{ Household Size } & $3-5$ & 10.2 & 16.33 & 10.42 & 22.45 & 14.85 \\
\hline & & $5-7$ & 38.78 & 24.49 & 25 & 28.57 & 29.21 \\
\hline & & 7-9 & 30.61 & 34.69 & 37.5 & 26.53 & 32.3325 \\
\hline & & $\geq 10$ & 20.41 & 24.49 & 27.08 & 22.45 & 23.6075 \\
\hline & Total & & 100 & 100 & 100 & 100 & 100 \\
\hline \multirow{5}{*}{5} & \multirow{4}{*}{ House Area $\left(\mathrm{m}^{2}\right)$} & 150 & 22.45 & 20.41 & 14.58 & 42 & 24.86 \\
\hline & & $150-300$ & 40.82 & 38.78 & 54.17 & 42 & 43.9425 \\
\hline & & $300-500$ & 26.53 & 20.41 & 16.67 & 12 & 18.9025 \\
\hline & & $\geq 500$ & 10.2 & 20.4 & 14.58 & 4 & 12.295 \\
\hline & Total & & 100 & 100 & 100 & 100 & 100 \\
\hline \multirow{4}{*}{6} & \multirow{3}{*}{ Building Type } & $\begin{array}{l}\text { Traditional } \\
\text { mud }\end{array}$ & 32.65 & 22.45 & 18.75 & 36.73 & 27.645 \\
\hline & & Bricks & 42.86 & 44.9 & 41.67 & 34.7 & 41.0325 \\
\hline & & Concrete & 24.49 & 32.65 & 39.58 & 28.57 & 31.3225 \\
\hline & Total & & 100 & 100 & 100 & 100 & 100 \\
\hline \multirow{5}{*}{7} & \multirow{4}{*}{$\begin{array}{l}\text { Property Value } \\
\text { (USD) }\end{array}$} & $\leq 20,000$ & 4.08 & 12.24 & 12.5 & 18.37 & 11.7975 \\
\hline & & $20,000-50,000$ & 51.02 & 30.62 & 39.58 & 48.98 & 42.55 \\
\hline & & $50,000-99,000$ & 30.61 & 34.69 & 22.92 & 12.24 & 25.115 \\
\hline & & $\geq 100,000$ & 14.29 & 22.45 & 25 & 20.41 & 20.5375 \\
\hline & Total & & 100 & 100 & 100 & 100 & 100 \\
\hline
\end{tabular}


Table 1. Cont.

\begin{tabular}{|c|c|c|c|c|c|c|c|}
\hline \multirow{2}{*}{ No. } & \multirow{2}{*}{ Characteristic } & \multirow{2}{*}{ Category } & District 1 & District 5 & District 6 & District 16 & Total. \\
\hline & & & $\%$ & $\%$ & $\%$ & $\%$ & $\%$ \\
\hline \multirow{4}{*}{8} & \multirow{3}{*}{$\begin{array}{l}\text { Residential } \\
\text { Status }\end{array}$} & $\begin{array}{c}\text { Own } \\
\text { (purchased) }\end{array}$ & 51.02 & 56 & 64.58 & 46.94 & 54.635 \\
\hline & & Mortgage & 38.78 & 38 & 27.09 & 42.86 & 36.6825 \\
\hline & & $\begin{array}{c}\text { Own } \\
\text { (inherited) }\end{array}$ & 10.2 & 6 & 8.33 & 10.2 & 8.6825 \\
\hline & Total & & 100 & 100 & 100 & 100 & 100 \\
\hline \multirow{4}{*}{9} & \multirow{3}{*}{ Settlement Type } & Planned area & 30 & 56 & 50 & 42 & 44.5 \\
\hline & & $\begin{array}{c}\text { Informal } \\
\text { settlement }\end{array}$ & 66 & 44 & 50 & 58 & 54.5 \\
\hline & & Slum & 4 & 0 & 0 & 0 & 1 \\
\hline & Total & & 100 & 100 & 100 & 100 & 100 \\
\hline
\end{tabular}

Initially, the informal settlement development was due to a series of social disruptions in the country that led to a wave of displacement and migration, in addition to existing formal urban planning policies and regulations not being able to cope with the pace of the growth. Recently, since 2005, the development has continued as a tradition because majority of the residents believed further employment opportunities would be provided as well as the opportunity to own cheap houses and with easy access to the city center. While residents have been provided electricity and water, there is a lack of parks and other public facilities, and according to the survey, the residents are of the opinion that the main priority is the improvement of the streets and sidewalks (Figure 6).

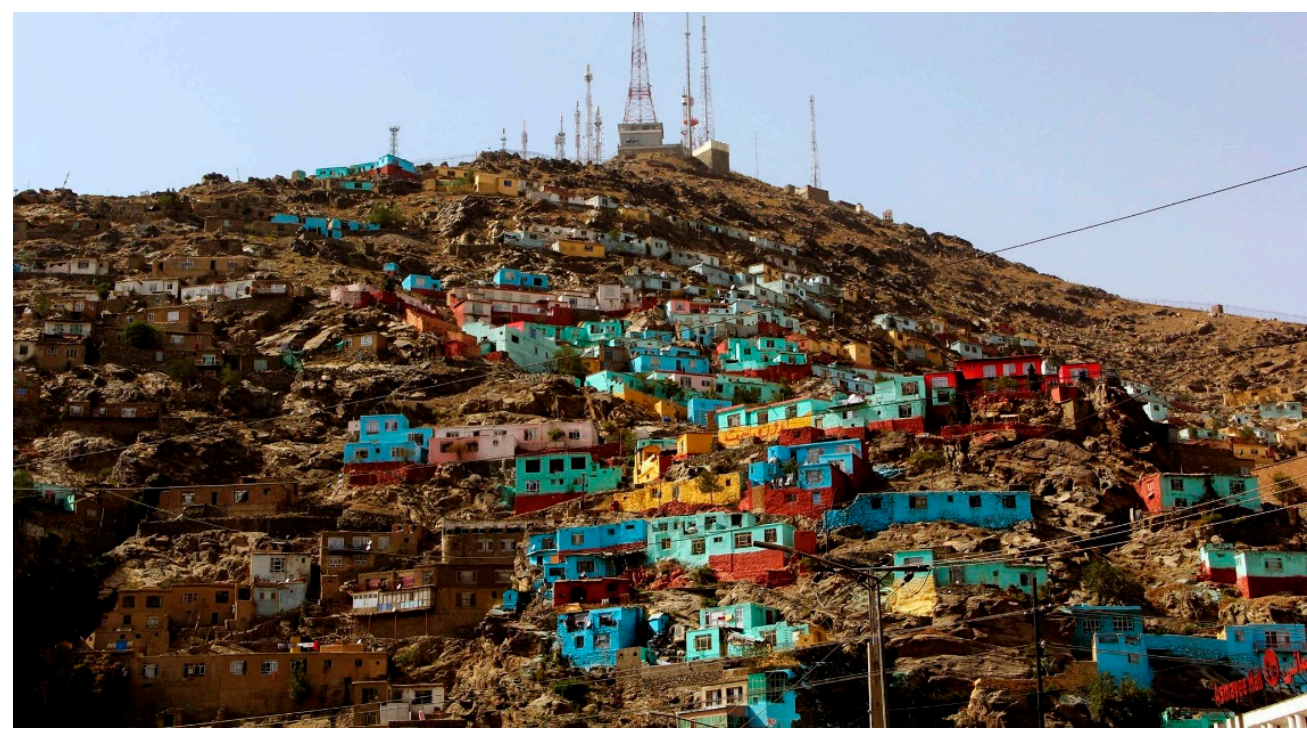

Figure 6. A view showing traditional settlement sprawling up a mountain slope. Photo by Capital Region Independent Development Authority (CRIDA), 2018; used with permission.

A brief description of the income composition of respondents in the study areas reveals that $54.81 \%$ of the residents have a low income, $40.06 \%$ have a middle income, and $5.13 \%$ have a high income. This implies that a wide percentage range of residents accommodated in informal settlements are in the low- to middle-income groups.

The findings of the statistical analysis focused on the weighted mean, mode, and standard deviation to structure the relative importance of the indicators, while investigating the priorities in the respondents' views. The calculated "weighted mean" value represents the degree of importance 
of an evaluated sub-criterion; the lower the "weighted average" value, the higher the degree of importance. The infrastructure and facilities' adequacy results (Table 2) show that the residents are suffering from generally inadequate availability of facilities and infrastructure in Kabul City. Upon further questioning, we found that respondents consider inadequate recreational facilities to be the most important factor for improving the built environment's condition. Recreational areas improve peoples' wellbeing and health, helping them avoid such conditions as depression as well as mitigating the effects of the dust and sandstorms.

Table 2. Infrastructure, facilities, and environmental adequacy survey in Kabul City Study area (based on author's 2018 fieldwork).

\begin{tabular}{|c|c|c|c|c|c|c|c|c|c|c|}
\hline \multicolumn{8}{|c|}{$\begin{array}{c}\text { Very Inadequate }=1, \text { Inadequate }=2, \text { Neutral }=3, \\
\text { Adequate }=4, \text { Very Adequate }=5\end{array}$} & \multirow[t]{2}{*}{$\begin{array}{l}\text { Weighted } \\
\text { Mean }\end{array}$} & \multirow[t]{2}{*}{ Mode } & \multirow[t]{2}{*}{$\begin{array}{l}\text { Standard } \\
\text { Deviation }\end{array}$} \\
\hline No. & Characteristic & Item & 1 & 2 & 3 & 4 & 5 & & & \\
\hline \multirow{5}{*}{1} & \multirow{5}{*}{ Public Facility } & Education & 14 & 136 & 25 & 20 & 5 & 2.33 & 2 & 0.84 \\
\hline & & Recreational & 160 & 25 & 8 & 4 & 3 & 1.33 & 2 & 0.77 \\
\hline & & Health & 62 & 108 & 21 & 5 & 4 & 1.91 & 2 & 0.83 \\
\hline & & Cultural & 6 & 32 & 74 & 71 & 13 & 3.27 & 2 & 0.91 \\
\hline & & Administrative & 41 & 27 & 93 & 37 & 2 & 2.66 & 2 & 1.03 \\
\hline \multirow{5}{*}{2} & \multirow{5}{*}{ Infrastructure } & Road & 5 & 167 & 14 & 4 & 7 & 2.19 & 2 & 0.67 \\
\hline & & $\begin{array}{c}\text { Traffic } \\
\text { congestion }\end{array}$ & 155 & 13 & 22 & 4 & 3 & 1.41 & 2 & 0.87 \\
\hline & & Drainage & 13 & 154 & 13 & 13 & 5 & 2.21 & 2 & 0.76 \\
\hline & & Electricity & 16 & 165 & 12 & 2 & 3 & 2.05 & 2 & 0.56 \\
\hline & & Water & 3 & 42 & 97 & 42 & 14 & 3.11 & 2 & 0.86 \\
\hline \multirow{3}{*}{3} & \multirow{3}{*}{ Environment } & Greenery & 19 & 139 & 28 & 5 & 6 & 2.19 & 2 & 0.76 \\
\hline & & $\begin{array}{c}\text { Waste } \\
\text { management }\end{array}$ & 121 & 42 & 22 & 8 & 4 & 1.64 & 2 & 0.96 \\
\hline & & $\begin{array}{l}\text { Pollution } \\
\text { control }\end{array}$ & 145 & 35 & 11 & 4 & 2 & 1.39 & 2 & 0.76 \\
\hline
\end{tabular}

This factor was followed by traffic congestion and pollution control, other significant priorities in both residential and mixed-use areas. Residents considered these factors as more challenging than others and felt that they should be addressed to mitigate pollution. Because mitigating traffic congestion was considered a significant priority by respondents even though Kabul is the capital and the largest city in Afghanistan, it is expected that traffic will be a major issue to address, as the city is experiencing rapid urbanization and population growth that is the highest in the region. Hence, the city has become more crowded. Recently, Afghanistan's National Environment Protection Agency has been focusing on finding effective solutions for controlling air pollution (Kabul Municipality) $[19,20]$.

The findings indicate that the respondents are very concerned about many of the items related to each characteristic, including the provision of services and facilities and the remaining issues in urban development such as inadequate waste management, public health services, and the network of roads or streets.

In the table weighted mean is analyzed as follows:

$$
\text { Weighted mean }=\frac{\sum_{i=1}^{n}(x i * w i)}{\sum_{i=1}^{n} w i}
$$

which expands to

$$
x=\frac{w 1 x 1+w 2 x 2+\cdots+w n x n}{w 1+w 2+\cdots+w n}
$$

where $\sum$ denotes the sum, $(w)$ is the weights and $(x)$ is the value. 
Statistics show that, currently, over $70 \%$ of the urban population in Kabul city are living in low-income, informal settlements with a poor environment [21], which has critical effects on sustainable development. The study area can simply be described as squatter settlements based on resident's dissatisfaction. Considering the findings of this study with practical and theoretical evidence of the study area shows that there is a significant relationship between culture and the studied socio-economic characteristics. As the residents continue to develop their community without change, it is most likely to influence the built environment and quality of life. Consequently, the study area requires social and cultural strategies to mitigate current unsustainable trends of poor infrastructure, degraded public facilities and inadequate services. The study recommends strategies for culturally sustainable development.

Culture refers here not to particular types of knowledge, but to fundamental new processes of social learning that are nourishing, healing, and restorative. Sustainability exists thus as a process of community-based thinking that is pluralistic, where culture represents both problem and possibility, form and process, and concerns those issues, values and means whereby a society or community may continue to exist (Dessein et al., 2015) [22].

\section{Discussion}

Understanding residents' views is important in order to achieve SUD. Their perceptions, priorities, and ambitions reflect their experience of everyday activities, quality of life, and continuity in traditional ways of development regarding current urban challenges, whereas culture-led upgrading has been widely adopted by developing cities as an important component of urban renewal and sustainable development. In recent years, cities have been gradually integrating culture as one of the cores of sustainable planning and policy discussions. Culture is also becoming a part of the emerging sustainable development model [23]. Cultural regeneration refers to "the continued support and strengthening of local cultural processes and structures" [24] (p. 396). At the same time, culture is seen as an important means of improving urban competitive advantages and solving political, social, and economic problems in urban areas, thus creating unprecedented importance [25].

There is no doubt that the traditional built environment should be reinterpreted and represented by considering present needs and ways of life. To address these challenges, a comprehensive SUD strategy is proposed on the basis of this study, particularly the research framework and our findings relevant to the study area. Our study illustrates a culturally responsive strategy to deal with the challenges of a sustainable built environment in Kabul City, as follows:

- Inclusive upgrading strategy

This people-oriented strategy should involve the residents' diverse socioeconomic status, which is a significant element of urban sustainability, infrastructure adequacy, and social inclusion that should be a major consideration in the design, development, and provision of sustainable urban growth in the study areas. It emphasizes an integrated socioeconomic and environmental urban renewal approach (upgrading and renovation) and is a socioeconomic support strategy that will promote environmental change in the study area. This approach is how the Ministry of Urban Development and Land, the Capital Region Independent Development Authority, and the Kabul Municipality can confront the challenges of unplanned construction in Kabul City, thereby improving housing conditions and accessibility and empowering the city's local economy [26]. Our research suggests that SUD should engage the private sector and public-private partnerships as well as nongovernmental organizations that will integrate socioeconomic and environmental factors to improve the living conditions of challenged urban areas.

- Contribution of culture to urban upgrading and renovation

Local communities and precincts can play important roles in several programs, which are expected to become important factors in urban upgrading and renovation. The sociocultural conditions, beliefs, 
and practices of the residents should be adequately taken into consideration when implementing the integration and urban renewal regularization. Building styles, strategy, and materials should be adopted and regularized in a way that recognizes the sociocultural and economic activities of the people without bias or prejudice toward sustainable development [27].

- Economic empowerment for urban development

A poverty reduction strategy is needed to promote economic empowerment, thereby also helping SUD. The gap between the rich and the poor should be reduced to the barest minimum, if not eradicated, to encourage every citizen's desire to own quality facilities and living environments. Economic limitations on access to affordable living should be abolished, and a policy of equity and equality in access to services and facilities should be adopted [23]. The integration of informal settlements or their regularization has recently been considered as a top priority of the government. Implementing this strategy is essential because the urban informal settlement activities are currently insignificant; thus, their integration is necessary. Developers should be encouraged through tax rebates to build affordable housing, infrastructure, and facilities with high-quality local materials.

\section{Conclusions}

Again, from the point of view of the larger geographical scale, the culturally responsive built environment in Kabul City has reached a turning point: like the environment, traffic congestion and growing population have become serious concerns and put tremendous pressure on both the environment and urban dwellers. It is therefore important to find ways or new lifestyles such as sustainable urban planning formulations that are more flexible, inclusive, and sustainable. We believe that research frameworks, technical requirements, and our findings not only provide new insights into the functioning of current growth construction or management principles but also could be used as feasible and important criteria for practical planners or official decision units to facilitate urban sustainability even further.

To increase the role of culture in urban development, the following complex measures should be taken:

- The modification of legislation concerning urban upgrading and renovation.

- The development of an expert community and the exchange of experiences on a local/municipality and national level.

- The development of public-private partnership structures and the attraction of private capital.

- The development of mechanisms to stimulate cultural and creative industries, including legal and economic measures.

- The creation of a dialogue among government, business, experts, and residents.

To address the significant issues involved in achieving SUD, there is an essential need to raise public awareness of sustainable development goals and the consequences of the continuity of current urbanization trends.

Author Contributions: O.H. has developed the theory, conducted survey and performed the analysis. Y.K. verified the analytical methods, encouraged O.H. to investigate the role of culture in the built environment and supervised the findings of this work. Both authors have read and agreed to the published version of the manuscript.

Funding: This research received no external funding.

Acknowledgments: The authors appreciate the support of the Capital Region Independent Development Authority (CRIDA) and United Nation Habitat in Kabul, Afghanistan. This research was funded by Japan International Cooperation Agency (JICA).

Conflicts of Interest: The authors declare no conflict of interest regarding the publication of this paper. 


\section{References}

1. Randolph, J.J. A guide to writing the dissertation literature review. Pract. Assess. Res. Eval. 2009, 14, 1-3.

2. Rakodi, C. Governance and civic engagement: Urban economies, poverty and civil society. J. Int. Dev. 2001, 13, 985. [CrossRef]

3. Payne, G.; Devas, N.; Rakodi, C. Managing Fast Growing Cities: New Approaches to Urban Planning and Management in the Developing World (Book Review). Third World Plann. Rev. 1995, 17, 111. [CrossRef]

4. International Young Nature-Friends. Sustainable Development and Its Challenges in Developing Countries; International Young Nature-Friends: Nové Město, Czech Republic, 2019; p. 12.

5. Wu, S.R.; Fan, P.; Chen, J. Incorporating culture into sustainable development: A cultural sustainability index framework for green buildings. Sustain. Dev. 2016, 24, 64-76. [CrossRef]

6. Afghanistan Public Policy Research Organization. Migration and Urban Development in Kabul: Classification or Accommodation? Afghanistan Public Policy Research Organization: Kabul, Afghanistan, 2012.

7. Najimi, A.W.; Leslie, J. Urban Recovery: The Case of Historic Kabul, Heritage and Sustainability in the Islamic Built Environment; Washington State University: Washington, DC, USA, 2012; pp. 23-37.

8. Kazimee, B.A. Traditional and Continuity in the Built Environment, Heritage and Sustainability in the Islamic Built Environment; WIT Press: Southampton, UK, 2012; pp. 63-82.

9. Kagan, S.; Hauerwaas, A.; Holz, V.; Wedler, P. Culture in sustainable urban development: Practices and policies for spaces of possibility and institutional innovations. City Cult. Soc. 2018, 13, 32-45. [CrossRef]

10. Kagan, S. Cultures of sustainability and the aesthetics of the pattern that connects. Futures 2010, 42, $1094-1101$. [CrossRef]

11. Worts, D. Fostering a culture of sustainability. Mus. Soc. Issues 2006, 1, 151-172. [CrossRef]

12. Smith, M.K. Towards a cultural planning approach to regeneration. In Tourism, Culture and Regeneration; Cromwell Press: Trowbridge, UK, 2007; pp. 1-9.

13. United Nations Development Program. Assessment of Development Results Afghanistan Report; United Nations Development Program: New York, NY, USA, 2014.

14. Samuel Hall Consulting [Internet]. Sustaining the Working Poor in Kabul Informal Settlements: An Evaluation of Solidarities International's Vocational Training Programme. Commissioned by Solidarités International. December 2012. Available online: https://static1.squarespace.com/static/5cfe2c8927234e0001688343/t/ 5d42ec3b9e2680000167eeb1/1564666977187/Sustaining-the-Working-Poor-in-the-Kabul-Informal-Settlements. pdf (accessed on 15 January 2020).

15. UN-Habitat. Strategic Nahia Action Plan (SNAP); UN-Habitat: Nairobi, Kenya, 2017.

16. SASAKI. Kabul Urban Design Framework-Executive Summary. 2018. Available online: http://www.sasaki. com/project/472/kabul-urban-design-framework/ (accessed on 12 December 2019).

17. Kazimee, B.A. Tradition and continuity in the built environment: Towards a housing model for Kandahar, Afghanistan. In Heritage and Sustainability in the Islamic Built Environment; WIT Transactions on State-Of-The-Art in Science and Engineering; Washington State University: Washington, DC, USA, 2016; pp. 63-82.

18. Prescott, M.; Vollmer, D.; Heisel, F. Informal urbanism: A source of information. Gaz. Future Cities Lab. 2013, 20, 1-2. [CrossRef]

19. Mitchell, G.; May, A.; McDonald, A. PICABUE: A methodological framework for the development of indicators of sustainable development. Int. J. Sustain. Dev. World 1995, 2, 104-123. [CrossRef]

20. Murphy, K. The social pillar of sustainable development: A literature review and framework for policy analysis. Sustain. Sci. Pract. Policy 2012, 8, 15-29. [CrossRef]

21. Majale, M. Afghanistan Housing Profile; UN-Habitat: Nairobi, Kenya, 2017; p. 100. ISBN 978-92-1-131927-9.

22. Dessein, J.; Soini, K.; Fairclough, G.; Horlings, L. (Eds.) Culture in, for and as Sustainable Development; University of Jyväskylä: Jyväskylä, Finland, 2015; ISBN 978-951-39-6177-0.

23. Hawkes, J. The Fourth Pillar of Sustainability: Culture's Essential Role in Public Planning; Common Ground Publishing Pty Ltd.: Gold Coast, Australia, 2001.

24. Duxbury, N.; Cullen, C.; Pascual, J. Cities, culture and sustainable development. In Cultures and Globalization: Cities, Cultural Policy and Governance; Anheier, H.K., Isar, Y.R., Eds.; Sage: London, UK, 2012; pp. 73-86.

25. Richards, G.; Palmer, R. Eventful Cities: Cultural Management and Urban Revitalization; Butterworth-Heinemann: Amsterdam, The Netherlands, 2010. 
26. Yudice, G. The Expediency of Culture: Uses of Culture in the Global Era; Duke University Press: Durham, NC, USA, 2003.

27. Beall, J.; Schütte, S. Urban Livelihoods in Afghanistan; Afghanistan Research and Evaluation Unit: Kabul, Afghanistan, 2016; pp. 1-68. Available online: https://areu.org.af/publication/626/ (accessed on 5 January 2020). 